\title{
COVID-19 impact on birth rates: first data from Metropolitan City of Genoa, Northern Italy
}

\author{
Aldo Franco De Rose ${ }^{1} \cdot$ Guglielmo Mantica ${ }^{1}$ - Francesca Ambrosini $\left(^{1}{ }^{1} \cdot\right.$ Rafaela Malinaric $^{1} \cdot$ Federica Balzarini $^{1}$. \\ Riccardo Banchero ${ }^{1} \cdot$ Carlo Terrone $^{1}$
}

Received: 15 February 2021 / Revised: 12 March 2021 / Accepted: 30 March 2021 / Published online: 12 April 2021

(c) The Author(s), under exclusive licence to Springer Nature Limited 2021

\section{To the Editor:}

The SARS-CoV-2 pandemic has brought enormous change in our personal lives and in the lives of the communities themselves. Almost all countries have imposed severe lockdowns to limit the spread of the virus. Northern Italy was one of the most affected areas globally, especially during the spring of 2020. A total lockdown was placed in this region starting from 10 March to 4 May 2020, followed by a gradual reopening in the subsequent weeks.

It has been hypothesized that the SARS-CoV-2 pandemic could impact the population worldwide, not only by having devastating effects on mortality but also in terms of declining birth rates. However, no reports have been published regarding birth rates in the ongoing pandemic and following restrictive measures.

We compared the number of births occurring between November 2019 and January 2020 with the respective months in 2020 and 2021 ( 280 days from the start and end dates of the first Italian lockdown) in Metropolitan City of Genoa, northern Italy.

From November 2019 to January 2020, there were 875 births in the City of Genoa (Fig. 1), while during the same period of the following year, there were only 770 births, with 105 fewer births (12\%). It could be argued that a gradual and progressive reduction in births has been observed in Italy during the last past decades; therefore, a large part of this important decrease may not be due only to the impact of the pandemic and restrictive measures themselves. It is difficult to quantify how much COVID-19

Francesca Ambrosini

f.ambrosini1@gmail.com

1 Department of Urology, Policlinico San Martino Hospital, University of Genoa, Genova, Italy might have affected this on-going trend. However, in 2019, according to the latest national report of the National Institute of Statistics (ISTAT), 420,084 births were registered in the country, almost 20,000 fewer than in the previous year, with a reduction of $\sim 4 \%$. Considering the city of Genoa to have a population of 854,000 people and Italy of $\sim 60$ million, if this trend of a decline in the birth rate is confirmed nationally, we could expect a decrease of over 50,000 units compared to the previous year (data sources: Press Room, Genoa City Hall. https://www.istat.it/it/a rchivio/nascite).

On the other hand, we should sound a note of caution with regard to such findings.

There are several reasons why COVID-19 and preventive measures could have affected the birth rates. First, the necessary restrictions on freedom of movement might have led to a decrease in the frequency of sexual intercourse, both in healthcare professionals and the general population, inevitably reducing the chances of conception [1]. Second, the restrictive measures introduced by many countries have led to an unavoidable reduction in gross domestic product (GDP) with loss of jobs and declines in profitability and employee wages, particularly in certain sectors. These, coupled with emotions such as melancholy, fear and uncertainty about the future that characterized this historical epoch, may have led to a lowered desire for pregnancy [2].

Last, due to healthcare system overload [3] and government-issued recommendations to contain the spread of SARS-CoV-2, many non-urgent medical-care services have been temporarily reduced or completely suspended. In the majority of healthcare facilities, only emergency surgery and non-surgical oncological treatments have been guaranteed, and unfortunately, at times, even those were delayed. Therefore, due to reduced outpatient andrology consultations, it is understandable how men's health has been negatively impacted. Similarly, fertility centres reduced their activities, postponing most medically assisted procreation procedures [4]. 
Birth rates - Metropolitan City of Genoa

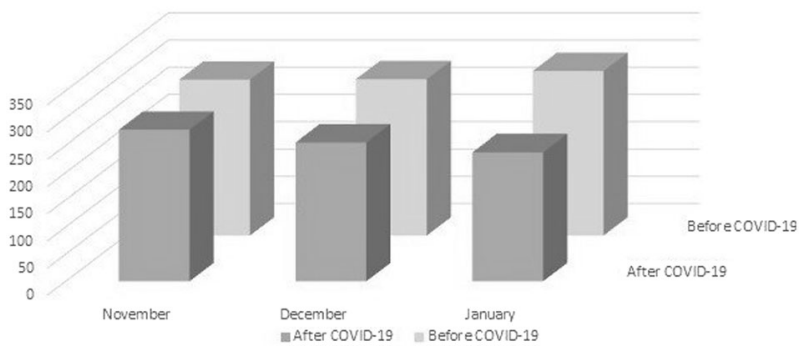

Fig. 1 Birth rates of the City of Genoa. The figure highlights the birth rates of the City of Genoa from November 2019 to January 2020 (before COVID-19) and during the same period of the following year (after COVID-19).

We are aware that our data may have several limitations and may somehow be influenced by local factors, thus not fully reflecting the reality of other communities. However, we observed a substantial downward trend in birth rates.

Considering all these elements, immediate fertility rebound and birth rate escalation after the end of the COVID-19 pandemic are more than desirable, as was the case after many other previous catastrophic events [5].

Acknowledgements Dr Claudio Critelli is acknowledged for the kind support in providing birth rate data from Metropolitan City of Genova. The ISTAT Istituto Nazionale di Statistica is acknowledged for providing data regarding Italian birth rates https://www.istat.it/it/a rchivio/nascite (Press Room, Genoa City Hall).

\section{Compliance with ethical standards}

Conflict of interest The authors declare no competing interest.

Publisher's note Springer Nature remains neutral with regard to jurisdictional claims in published maps and institutional affiliations.

\section{References}

1. Cocci A, Giunti D, Tonioni C, Cacciamani G, Tellini R, Polloni G, et al. Love at the time of the Covid-19 pandemic: preliminary results of an online survey conducted during the quarantine in Italy. Int J Impot Res. 2020;32:556-7.

2. De Rose AF, Chierigo F, Ambrosini F, Mantica G, Borghesi M, Suardi N, et al. Sexuality during COVID lockdown: a crosssectional Italian study among hospital workers and their relatives. Int J Impot Res. 2021;33:131-6.

3. Leonardi R, Bellinzoni P, Broglia L, Colombo R, De Marchi D, Falcone L, et al. Hospital care in Departments defined as COVIDfree: a proposal for a safe hospitalization protecting healthcare professionals and patients not affected by COVID-19. Arch Ital Urol Androl. 2020;92.

4. Rizzo M, Liguori G, Verze P, Palumbo F, Cai T, Palmieri A. How the andrological sector suffered from the dramatic Covid 19 outbreak in Italy: supportive initiatives of the Italian Association of Andrology (SIA). Int J Impot Res. 2020;32:547-8.

5. De Rose AF, Gallo F, Parisini B, Timossi L, Bertolotto F, Nordio A, et al. The influence of Genoa G8 events on people sexuality. Arch Ital Urol Androl. 2004;76:25-8. 